\section{Rabdomiolisis secundaria al uso de electroestimulación muscular}

\section{Resumen}

Presentamos el caso de una mujer joven que desarrolló una rabdomiolisis tras someterse a electroestimulación con fines estéticos. La rabdomiolisis es una condición infrecuente en personas jóvenes y no se han descrito más que un caso secundario al uso prolongado de este tipo de dispositivos de electroestimulación.
Alina Boteanu1,2, Adela Braña Cardeñosa², Ana Espejo ${ }^{3}$

1 Reumatólogo. Servicio de Reumatología, Hospital Universitario Ramón y Cajal.

2 M. Interna. Servicio de Urgencias, Hospital Universitario Ramón y Cajal.

3 Medicina Familiar y Comunitaria. Area Este.

Correspondencia:

झ al_boter@yahoo.com

\title{
Abstract
}

We present a case of a young woman who developed rhabdomyolysis after underwent a single session of muscle electrical stimulation over both arms with esthetic purposes. Rhabdomyolysis in young people is an infrequent condition and there is no more than one single case secondary to the extended use of a muscle electrical stimulation device.

\section{Presentación clínica}

Mujer de 34 años que consultó por urgencias por aumento de volumen de brazos y antebrazos de instauración rápida a lo largo de las últimas 72 horas tras el uso de un sistema de electroestimulación muscular sobre las extremidades superiores, tórax y abdomen con fines de entrenamiento deportivo.

La paciente estuvo expuesta al sistema durante 30 minutos aproximadamente. No refería exposición cutánea a cremas o lociones y no presentaba prurito.

No tenía antecedentes de enfermedad hepática o epilepsia previa, no era consumidora de sustancias ilegales y refería realizar actividad física deportiva de forma habitual fundamentalmente aeróbica.

A su llegada a urgencias presentaba aumento de volumen, dolor únicamente a la compresión muscular de brazos y antebrazos, y ligera debilidad en ambas extremidades superiores. La circunferencia de los 
brazos y antebrazos eran de $29 \mathrm{~cm}$ y $26 \mathrm{~cm}$ respectivamente (Fig. 1).

Los pulsos radiales eran simétricos y presentaba un llenado capilar normal.

No había datos de inestabilidad hemodinámica a su llegada a urgencias ni otros signos inflamatorios. La orina era colúrica.

En la primera valoración analítica presentaba creatinin fosfoquinasa (CPK) de $24000 \mathrm{U} / \mathrm{L}$. No hubo alteración de la función renal. Presentaba una determinación de alanin transaminasa (GOT) de 799 U/L (VN 4-50) y de asparto transaminasa (GPT) de 214 U/L (VN 5-40). La cifra de CPK aumentó a 34000 U/L a las 24 horas. Durante la hospitalización se realizó un seguimiento de la función renal y CPK. No se presentó ningún deterioro de la función renal y la CPK se redujo a $14000 \mathrm{U} / \mathrm{L}$ al cabo del cuar-

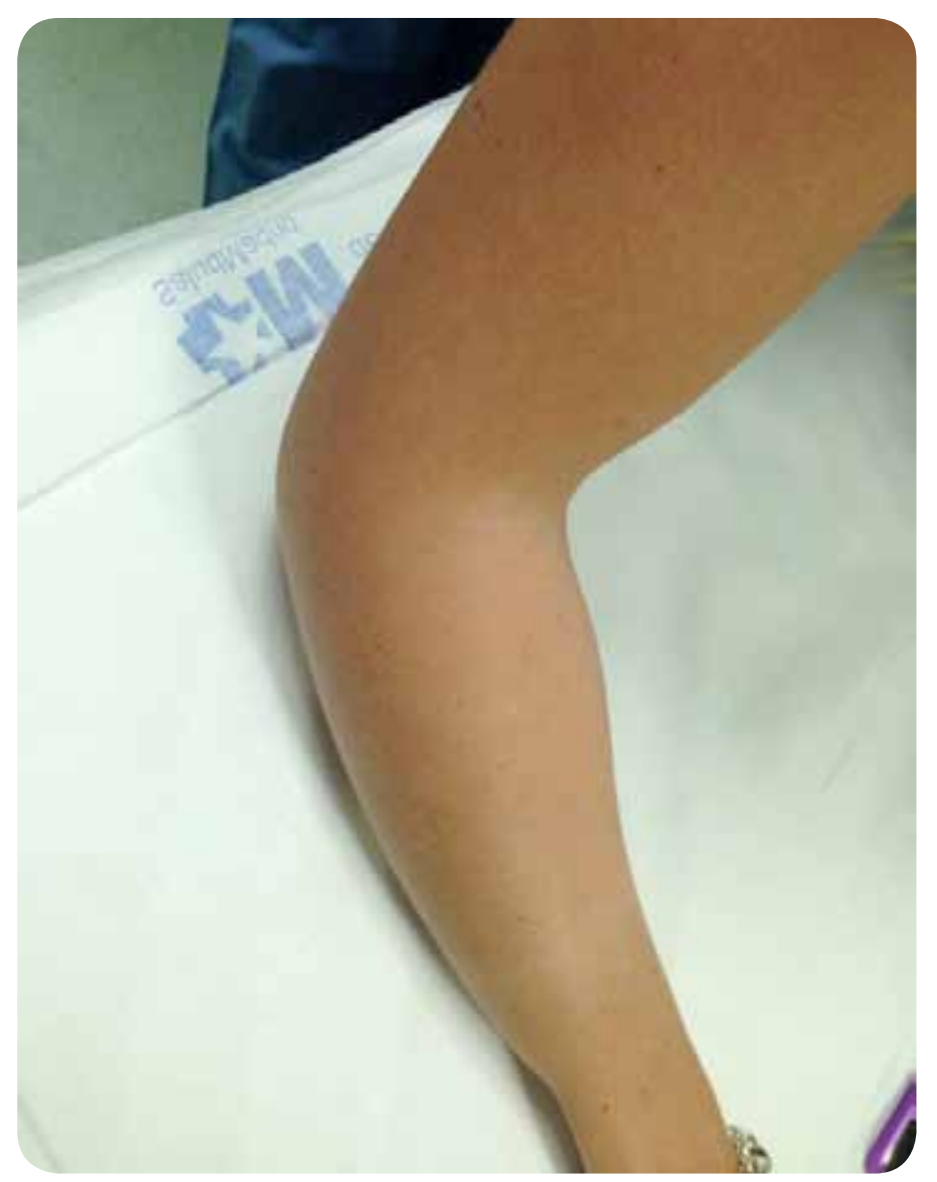

Figura 1. Imagen del brazo derecho de la paciente en la primera exploración, 72 horas después de la electroestimulación. to día de ingreso y 256 U/L al séptimo día. Ambas transaminasas se normalizaron al alta. Se realizaron pruebas serológicas para descartar infección por virus hepatotropos que resultaron negativas. En ese momento la circunferencia de brazos y antebrazos se redujo en $2 \mathrm{~cm}$.

\section{Discusión}

La rabdomiolisis secundaria al ejercicio es una condición clínica relativamente infrecuente en personas sanas, producida por la lisis celular de tejido muscular esquelético y que se caracteriza por la triada de dolor muscular, debilidad y oscurecimiento de la orina [1-3]. Es probable que su baja prevalencia obedezca a un infradiagnóstico. Su manejo es fundamentalmente de soporte, evitando el desarrollo de insuficiencia renal o limitándola mediante la sobrehidratación y controlando otras alteraciones iónicas potencialmente graves que se pueden relacionar con la lisis celular como la hiperpotasemia $[1,4,5]$. Se ha identificado que la realización de esfuerzos físicos extenuantes sin previo entrenamiento adaptativo es uno de los factores de riesgo más importantes para el desarrollo de esta condición con independencia del índice de masa corporal o sexo [6].

Este es el segundo caso descrito en la literatura de rabdomiolisis tras la realización de ejercicio físico por electroestimulación. El primer caso, descrito por Guarascio et al [5] presentó cifras de CPK inferiores a 3000 U/L y de GOT y GPT ligeramente incrementadas. En dicho caso el paciente había estado utilizando de forma sostenida un dispositivo de electroestimulación durante al menos tres meses. El caso que presentamos viene a ser el primero descrito en la literatura en la que una única exposición a este tipo de estimulación muscular genera rabdomiolisis. Teniendo en cuenta que el uso de aparatos de electroestimulación con fines estéticos se ha hecho frecuente en centros depor- 
tivos e incluso se distribuyen para uso domiciliario, la prevalencia de rabdomiolisis secundaria a su uso es, por ahora, insignificante. No obstante ello, cabe considerar esta etiología en casos de rabdomiolisis en pacientes jóvenes que se hayan expuesto a este tipo de dispositivos.

\section{Referencias}

1. Walsworth $M$, Kessler T. Diagnosing exertional rhabdomyolysis: a brief review and report of two cases. Mil Med. 2001;166(3):275-7.
2. Macdonald R, Rosner $Z$, Venters $H$. Case series of exerciseinduced rhabdomyolysis in the New York City jail system. Am J Emerg Med. 2014; 32(5):466-7

3. Parmar S, Chauhan B, DuBose J, Blake L. Rhabdomyolysis after spin class? J Fam Pract. 2012;61(10):584-6.

4. Moghtader J, Brady WJ Jr, Bonadio W. Exertional rhabdomyolysis in an adolescent athlete. Pediatr Emerg Care. 1997;13(6):382-5.

5. Guarascio P, Lusi EA, Soccorsi F. Electronic muscular stimulators: a novel unsuspected cause of rhabdomyolysis. Br J Sports Med. 2004;38(4):505; discussion 505.

6. Lin $\mathrm{H}$, Chie W, Lien $\mathrm{H}$. Epidemiological analysis of factors influencing an episode of exertional rhabdomyolysis in high school students. Am J Sports Med. 2006;34(3):481-6. 
Opina sobre este artículo:

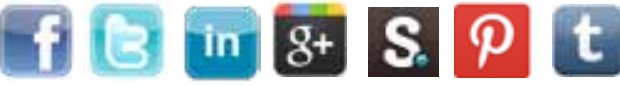

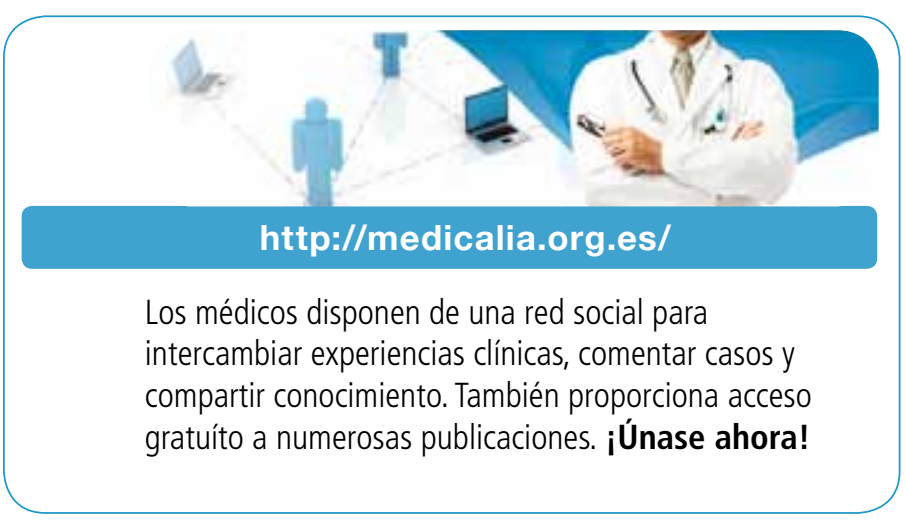

\section{Publish with iMedPub}

\section{http://www.imed.pub}

Acta Reumatológica es una revista que tiene por fin la difusión de estudios clínicos relacionados con aspectos prácticos del diagnóstico, tratamiento y seguimiento de pacientes con patología reumatológica, de estudios epidemiológicos relacionados con patología inflamatoria y musculoesquelética de presentación común o infrecuente en la práctica clínica tanto en población adulta como pediátrica, de casos clínicos de patología poco habitual o de presentaciones inhabituales de patología frecuente, de imágenes didácticas e ilustrativas en reumatología y del estado actual e innovación en la formación especializada en reumatología. 